Chemistry and Ecology

December 2005, Volume 21, Issue 6, pages 455 - 463

http://dx.doi.org/10.1080/02757540500438516

(c) 2005 Taylor \& Francis Group
Archimer http://www.ifremer.fr/docelec/ Archive Institutionnelle de l'Ifremer

The original publication is available at http://www.tandf.co.uk/journals/

\title{
Mytilus galloprovincialis as bioindicator in embryotoxicity testing to evaluate sediment quality in the lagoon of Venice (Italy)
}

\author{
Volpi Ghirardini Annamaria ${ }^{a}$, Losso Chiara ${ }^{a,{ }^{*}}$, Arizzi Novelli Alessandra ${ }^{a}$, Baugrave Alvise $^{a}$, Edouard \\ His $^{b}$, Ghetti Pier Francesco ${ }^{a}$
}

\footnotetext{
a Department of Environmental Sciences, University of Venice Campo della Celestia, Venice, Italy

b IFREMER DEL/PC2, Quai du Commandant Silhouette, Arcachon, France

*: Corresponding author : Losso C., email address : closso@unive.it
}

\begin{abstract}
:
The possibility of using Mytilus galloprovincialis from natural populations of the lagoon of Venice in toxicity bioassays based on embryo development, according to international standard methods, was investigated. In order to valuate this method for the lagoon, iterative steps including evaluation of reproducibility, sensitivity and discriminatory capacity towards some pure substances and environmental samples were performed. Evaluation of sensitivity towards a reference toxicant (copper) evidenced good replicability and repeatability. Results showed that natural population is better than hatchery population for performing bioassays. Evaluation of applicability to elutriates revealed that the method is able to discriminate among sediments of the lagoon of Venice at different typologies and levels of contamination, showing an important effect for almost all study sites.
\end{abstract}

Keywords: Bioassay; Reproducibility; Autochthonous population; Elutriates

\section{Introduction}

The use of biological indicators is becoming of increasing importance in evaluating the quality of sediments and their potential effects on the environment [1]. Selecting a toxicity test, the identification of test species and sample matrix, duration of test and measurement endpoints are needed [2], basing possibly on availability of standardized procedures [3, 4]. The search for the most representative species for specific areas of concern and specifically designed for estuarine conditions should aim at indigenous species instead of surrogate species [5]. Molluscs are considered the best candidates among marine organisms [6-8], as gametes are available for many months of the year in the Mediterranean area [9, 10]. The italian law has only recently established the need for short- and long-term toxicity bioassays for assessing 
marine-water quality (D.L. 152/99). Some standardized toxicity bioassays are available in Italy for freshwaters, but at present there is a shortage of standardized tests for coastal marine and transitional environments.

This work investigated the possibility of using Mytilus galloprovincialis from natural populations of the lagoon of Venice in toxicity bioassays based on embryo development, according to international standard methods. The aim of this work is to valuate this method for the lagoon by iterative steps including evaluation of reproducibility, sensitivity and discriminatory ability towards some pure substances and environmental samples.

A first step evaluated the intralaboratory reproducibility of method using a reference toxicant. Copper was selected as a reference toxicant because it answers to most requisites for a good reference toxicant [11] and has also been used in other bioassays [12-14]. Embryos from natural and hatchery populations of the lagoon were used for this study from November 2002 to May 2003.

A second step investigated the applicability of method to environmental samples using, as test matrices, elutriates from sediments of the lagoon. The potential effects of pollutants which are made available in the water column as a consequence of sediment resuspension (dredging, fishing gear, etc.) could be assessed using embryotoxicity data with the autochthonous M. galloprovincialis.

\section{Materials and methods}

\subsection{Animal sampling}

Adults of $M$. galloprovincialis were sampled from natural and hatchery populations of the lagoon of Venice. Samples were collected monthly from October 2002 to May 2003, according to the length of the reproductive period described for the populations of the North Adriatic Sea $[9,10]$. Natural and hatchery sites are very close, far from point sources of pollution, located near the sea inlet of Malamocco (figure 1). Adults from natural population were collected during high tide from artificial substrates 1.5-2 $\mathrm{m}$ deep, using a rake with a net. Adults from hatchery population (Mitilpesca s.r.l., Venice, Italy) were collected using a similar method, sampling starting from January when the animals had reached full maturity. Moreover, in order to compare lagoonal and open sea populations, sampling was also performed in a site ( $\mathrm{N} 45^{\circ} 18^{\prime} 53^{\prime \prime}, \mathrm{E} 12^{\circ} 30^{\prime} 30^{\prime \prime}$ ) some miles off the sea inlet.

Adults were transported to the laboratory in refrigerated containers and were cleaned and stored at $4{ }^{\circ} \mathrm{C}$ until testing.

\subsection{Embryotoxicity test}

The embryotoxicity test was performed according to the method proposed by His et al. [15], on the basis of the standard protocol of US EPA [16]. Adults were induced to spawn by thermic stimulation (temperature cycles at 18 and $28^{\circ} \mathrm{C}$ ). Gametes of good quality derived from the best males and females were selected and filtered at $32 \mu \mathrm{m}$ (sperm) and $100 \mu \mathrm{m}$ (eggs) to remove impurities. Eggs $(1000 \mathrm{ml})$ were fertilized by injecting $10 \mathrm{ml}$ of sperm; fecundation was verified by microscopy.

Egg density was determined by counting four subsamples of known volume. Fertilized eggs, added to test solutions in order to obtain a density of 10-20 eggs ml ${ }^{-1}$, were incubated for $48 \mathrm{~h}$ at $18^{\circ} \mathrm{C}$ and fixed with buffered formalin. Hundred larvae were counted, distinguishing between normal larvae (D-shaped) and abnormalities (malformed larvae and pre-larval stages). 
The acceptability of test results was based on negative control for a percentage of normal D-shaped larvae $\geq 80 \%$ [7].

Three replicates for each sample (nominal concentration for both copper and elutriates) were tested.

\subsection{Chemicals}

Dilution water (for test solutions and gametes) was artificial sea water reconstituted according to ASTM [17] at salinity of 34 ppt.

Copper solutions were prepared starting from a standard solution for atomic spectroscopy (1000 $\left.\mathrm{mg} \mathrm{l}^{-1}\right)$, composed of copper nitrate in nitric acid 0.5 M (Baker, Deventer, Holland).

To evaluate the possible influence of confounding factors in elutriate toxicity, ammonia and sulphide were analysed for each environmental sample. Concentrations of sulphides and total ammonia were measured with a spectrophotometer (mod.DR/2010, HACH, Loveland, CO, USA) using the methylene blue method (USEPA SM 4500-S2 D) for sulphides and the salicylate method [18] for total ammonia.

\subsection{Sediments sampling and elutriate preparation}

Sediment samples (20 cm superficial cores) were collected from 1998 to 2001 from 12 sampling sites in the lagoon of Venice (figure 1), covering different levels of pollution from the industrial zone to areas close to the sea inlet points, in order to test the ability of methods

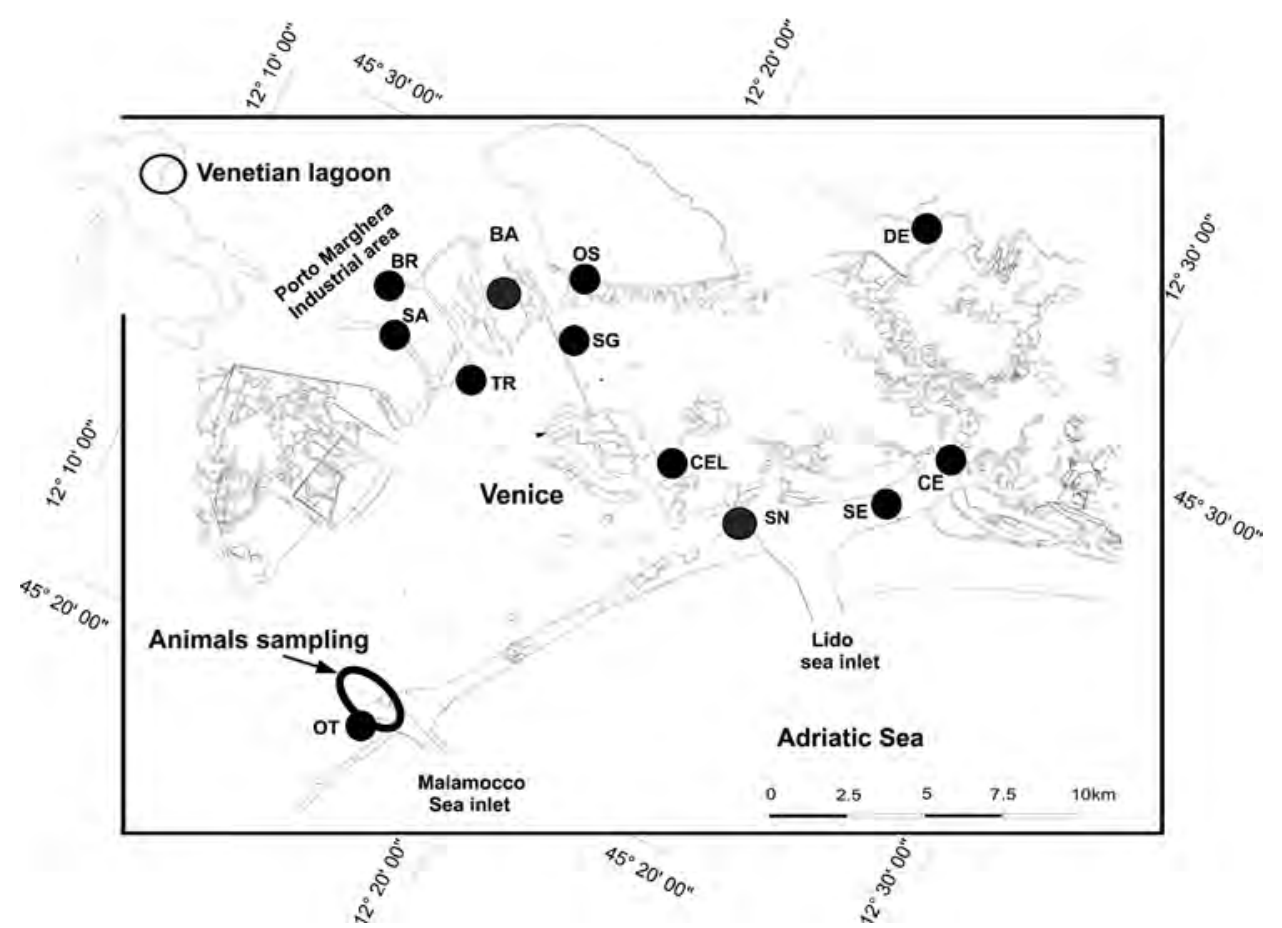

Figure 1. Study area in lagoon of Venice, Italy. Animals were collected from area within oval. Sediment sampling sites: OT, Ottagono; SE, S. Erasmo; SN, S. Nicolò; CE, Centrega Marsh; DE, Dese estuary; OS, Osellino Canal; BR, Brentelle Industrial Canal; SA, South Industrial Canal; BA, Brentella Canal; TR, Tresse; SG, San Giuliano; CEL, Celestia. 
in discriminating different pollution/bioavailability situations. A quality assurance/quality control procedure was performed in sediment sampling: at each station, the area (a circle with a diameter of approximately $30 \mathrm{~m}$, with a central point fixed by geographical coordinates), sample dimensions and number of replicates (three) were defined and an integrated sampling was carried out in order to take into account the possible spatial micro-variability in pollution/bioavailability [19].

Two sites were typically estuarine (DE, Dese; OS, Osellino) and influenced by pollutants coming from the mainland. In particular, Osellino is a highly polluted canal affected by multifactorial pollution, due to treated and untreated wastewaters from the town of Mestre and leaching from a recently reclaimed but uncontrolled landfill. Three sites were selected inside the Porto Marghera industrial area (BR, Brentelle Industrial Canal; SA, South Industrial Canal; BA, Brentella Canal) and one (TR, Tresse) just in front of it. Two subtidal sites (SG, S. Giuliano; CEL, Celestia) were chosen in points mainly influenced by mixed urban-industrial pollution. Four subtidal sites (OT, Ottagono; SE, S. Erasmo; SN, S. Nicolò; CEb, Centrega), close to the Malamocco and Lido sea inlet points, and an intertidal mudflat located in the northern part of the lagoon (CEa, Centrega) were selected as potential 'reference sites' (certainly not pristine) on the basis of available information on levels of sediment contamination and their distance from the point source of pollution. All these sites were investigated at least twice, with the exception of SN and BA, and in comparable seasonal periods (i.e. end of winter and end of summer). Samples were identified by letters for the sampling stations, followed by the season (w, winter; s, summer) and the year.

A classification of sampling sites can be made basing on the current quality criteria used to classify dredged sediments in the lagoon (Italian Ministry of the Environment, 1993), focused on sediment disposal (Class A: sediments can be used for restoration of lagoon morphology, in morphological structures with a direct contact with water; Class B: sediments can be used to restore lagoon islands, avoiding contaminants run-off from sediments; Class C: sediments can be used to raise islands, avoiding that sediments keep in contact with waters). According to a monitoring program performed by the Venice Water Authority [20], BA is the most polluted site, exceeding the Class $\mathrm{C}$ (the worst) both for organic and inorganic micropollutants; BR, OS and TR were very polluted sites too, as regards both organic and inorganic micropollutants (Class C), whereas SE, SN and OT (Class A for both categories, the best) can be put on the top of our quality gradient. CE also showed good chemical quality, with the exception of mercury levels. The other sites ranged from medium contamination levels (Class B) for both organics and inorganics (DE) to medium-high (Classes B and C) (SG, SA, CEL). Sites TR, SG, CEL and SE were included in the central basin, the most severely affected by hydraulic and/or mechanical dredges used for clam harvesting and recently documented as characterized by medium-high levels of solid suspension, according to remote sensing [21].

For elutriate preparation, a slurry with a 1:4 sediment:water (dry weight/volume) ratio was stirred $(230 \mathrm{rpm})$ at $4{ }^{\circ} \mathrm{C}$ in the dark for $24 \mathrm{~h}$ using a Jar test (Vittadini, Milan, Italy). After stirring, the sediment/water mixture was allowed to settle for $1 \mathrm{~h}$. The unsettled portion (due to the high clay content of lagoonal sediments) was centrifuged at 10,000 rpm (about $7700 \mathrm{~g}$ ) for $30 \mathrm{~min}$ at $4{ }^{\circ} \mathrm{C}$ [21]. The resulting elutriate was frozen until use. Toxicity tests were performed with elutriates in three replicates for each sample, using a geometrical scale $(6,12,25,50,75$, $100 \%$ of elutriate) for diluting samples.

\subsection{Data analysis}

Responses to each treatment (percentage of anomalies in embryo development) were corrected for effects in control tests by applying Abbott's formula [17]. 
Data for copper were expressed as EC50 values with 95\% confidence limits, calculated using the Trimmed Spearman-Karber statistical method [22]. For elutriates, the percentage of effect (that is, the percentage of anomalies observed on $100 \%$ of elutriate) was used for fewer toxic samples, whereas for more toxic samples, for which elutriate dilutions were needed, the TU50 (Toxic Unit $50=1 /$ EC50 $\times 100$ ) values were calculated [21].

\section{Results and discussion}

\subsection{Synthetic samples}

Experiments performed during November 2002 with two batches of natural population and one operator highlighted good replicability of methods. Indeed, EC50 values with 95\% confidence limits for copper for batch A were $0.18(0.17-0.19) \mu \mathrm{M}$ for the first replicate, $0.19(0.18-$ $0.20) \mu \mathrm{M}$ for the second and $0.20(0.20-0.21) \mu \mathrm{M}$ for the third, with a mean of $0.19(0.19-0.20)$ $\mu \mathrm{M}$ and a standard deviation of 0.01 . EC50 values for batch B were $0.19 \mu \mathrm{M}$ for the first replicate, $0.17(0.16-0.17) \mu \mathrm{M}$ for the second and $0.16(0.16-0.17) \mu \mathrm{M}$ for the third, with a mean of $0.20(0.19-0.20) \mu \mathrm{M}$ and a standard deviation of 0.02 .

The repeatability of the method was shown by experiments performed with natural population from November 2002 to May 2003, using 2 operators and 10 batches of organisms: the EC50 mean value with standard deviation for copper was $0.29 \pm 0.09 \mu \mathrm{M}(\mathrm{CV}=31 \%$, $n=10$ ) (figure 2).

Considering all experiments performed during the reproductive period, with 2 operators, 14 organism batches and 3 different sampling population (natural, hatchery, open sea), a reference control chart was constructed (figure 2). The EC50 mean value with standard deviation for copper was $0.28 \pm 0.08 \mu \mathrm{M}(\mathrm{CV}=27 \%, n=14)$. As a preliminary evaluation, embryotoxicity with autochthonous populations of $M$. galloprovincialis showed an acceptable intralaboratory reproducibility.

A first optimal range (2 standard deviations from the mean EC50 value) in which the EC50 should fall in subsequent tests was defined, using all data, with lower and upper control limits

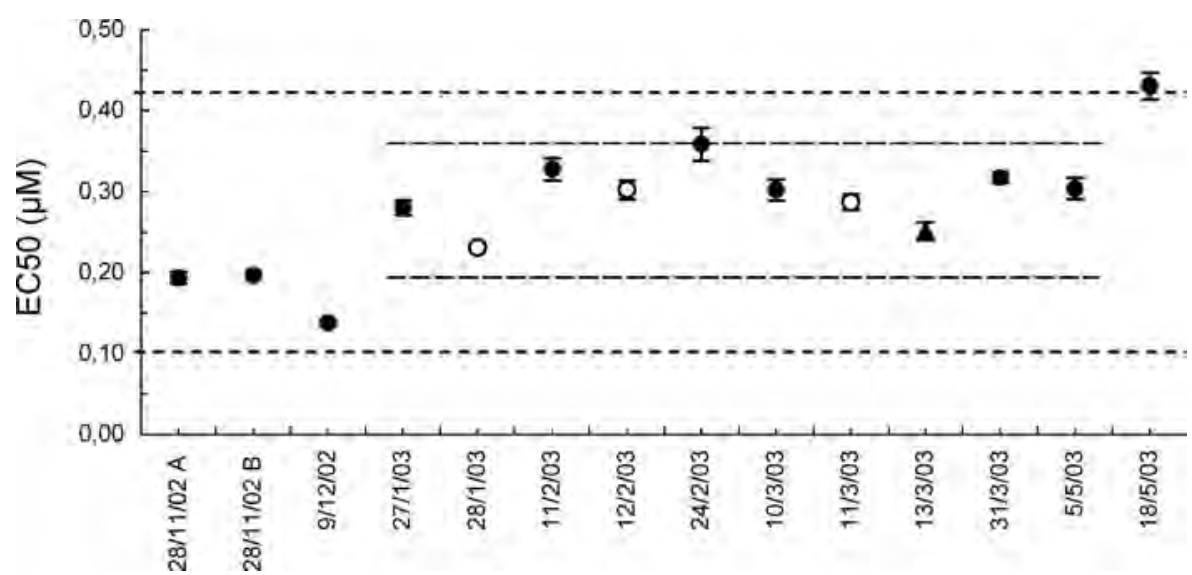

Figure 2. Control card for embryotoxicity test using copper as a reference toxicant. Black, natural population; white, hatchery population; star, marine population. Hatchery population did not develop D-shaped larvae according the acceptability criteria of the test (>80\% in negative control) in the following periods: 24 February 2003; 31 March 2003; 05 May 2003. Dotted lines evidenced acceptability ranges considering start and end of reproductive period (thicker) and central reproductive period (tighter dots). 
of 0.31 and $0.43 \mu \mathrm{M}$, respectively (thicker lines in figure 2). Considering only the central reproductive period, when the sensitivity of gametes may have been less variable, the range narrowed from 0.22 to $0.37 \mu \mathrm{M}$. Considering only the data close to this range, we can obtain a better intralaboratory reproducibility $(\mathrm{CV}=12 \%, n=10)$. Some observations may be made comparing monthly results from natural and hatchery populations. If the natural population of the Lagoon always yielded good gametes for bioassays, hatchery population did not develop normal D-shaped larvae according to the acceptability criteria of the test (at least $80 \%$ in negative control) on 24 February 2003, 31 March 2003 and 5 May 2003. Moreover, hatchery activities limited the reproductive period, because adult maturity started only from January (and not from October to November as in natural population). Therefore, these results showed that natural population is better for performing bioassays.

\subsection{Elutriates from lagoonal sediments}

Embryotoxicity results for elutriates are shown in figure 3, in which samples are arranged according to increasing toxicity. The upper graph reports data expressed as percentage of effect for the less toxic samples (undiluted elutriates); the lower graph ranks the most toxic samples for which toxic units (UT50) are calculable.

Five samples do not show evident toxicity with a percentage of effect lower than $5 \%$ (TRw01, CEL-w03, SA-w99, CEb-s98, SN-w03). Sample SE-w03, a possible reference site, shows a percentage of effect of 7\%. One group of samples (CEL-s01, OT-w01, SG-w01) has an embryotoxicity effect between $20 \%$ and 30\%; sample SA-s98, off the industrial area, shows a percentage of effect of $44 \%$. More toxic samples, with UT50 calculable ranging from 1 to 5.8, are those from estuarine sites (DE-s98, DE-w99; OS-s98, OS-w99), industrial sites (BR-s98, BR-w99; TR-s00, TR-w03) and a mixed pollution site (SG-s00), but also from the potential (according to chemical analyses) reference sites CE (CEb-w99, CEa-s98, CEaw99), OT (OT-s00) and SE (SE-s01). The most toxic sample was from the industrial canal of Brentella (BA-s01), with a UT50 value of 67.

The test shows a relevant effect for almost all sediment samples investigated and is able to discriminate among the sediments at different typologies and levels of contamination.

In order to verify whether possible confounding factors could contribute to toxicity of environmental samples, as suggested by recent literature regarding the quality evaluation of marine and coastal sediments [23-26], chemical analyses of sulphide and ammonia were made

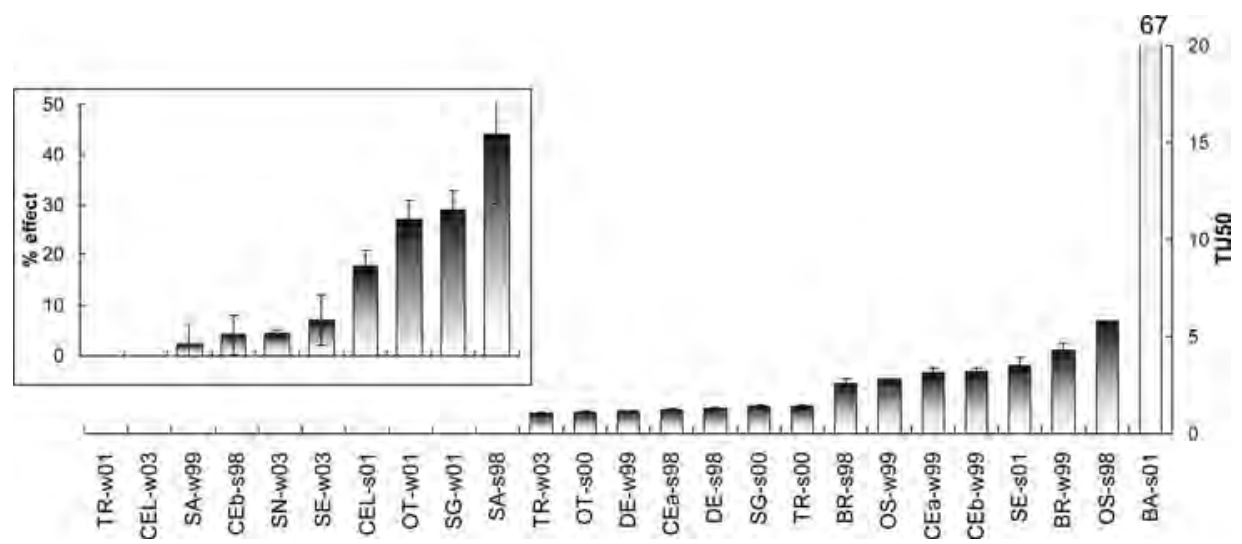

Figure 3. Embryotoxicity results for elutriates of sampling sites. (Above) Data are expressed as percentage of effect for less toxic samples; (below) most toxic samples for which toxic units (UT50) are calculable. 
on elutriates and a comparison between chemical concentration in elutriates and sensitivity limits of method towards ammonia and sulphide was carried out.

Sulphide concentrations in elutriates ranged from 0 to $0.078 \mathrm{mg} / 1$ and were lower than the NOEC value of $0.1 \mathrm{mg} / 1$ recommended by ASTM [17] for bivalve embryotoxicity tests. For ammonia, elutriates showed concentrations of total ammonia lower than the NOEC value of $4.7 \mathrm{mg} / 1$ (at $\mathrm{pH} 7.8-8.1$ ) for bivalve embryotoxicity tests, with the exception of OS-w99 (18 mg/l of total ammonia), BR-s98 (20 mg/l), BR-w99 (23 mg/l), OS-s98 (45 mg/l) and BA-s01 (160 mg/l). These high concentrations of total ammonia may be due to anthropogenic activities (industrial effluents and wastewater discharges) and due to degradation of organic matter; in this case ammonia, in our opinion, should be considered a contaminant itself.

For some elutriate samples, results obtained by M. galloprovincialis can be compared with those already found by using the embryotoxicity test with the sea urchin Paracentrotus lividus [21]. For OT site, sea urchin showed a toxicity of about $10 \%$ of effect in both sampling campaigns, whereas mussel evidenced that OT-s00 (TU50 = 1.1) is more toxic than OT-w01 ( $27 \%$ of effect). For the estuarine site DE, mussel registered a toxicity quite similar in both sampling campaigns (TU50 $=1.3$ for DE-s98 and TU50 $=1.2$ for DE-w99), whereas the sea urchin showed that DE-w99 (TU = 2) is more toxic than DE-s98 (TU50=1.2). Samples SAs98 and SA-w99 had a comparable toxicity for P. lividus (18\% and $24 \%$ of effect, respectively), whereas for M. galloprovincialis SA-s98 (44\% of effect) is more toxic than SA-w99 (2.4\% of effect). Both tests did not evidence toxicity in CEL-w03 but for CEL-s01 sea urchin showed $3.6 \%$ of effect, whereas mussel showed a higher toxicity of $18 \%$ of effect. About the industrial site TR, both tests showed no toxicity for TR-w01, the sea urchin highlighted low toxicity for TR-s00 (9\% of effect) and TR-w03 (21\% of effect), whereas the mussel registered higher toxicity of TU50 $=1.4$ for TR-s00 and of TU50 = 1 for TR-w03. For the potential reference sites, $P$. lividus showed absence of toxicity for $\mathrm{CEb}(0 \%$ of effect for $\mathrm{CEb}-\mathrm{s} 98$ and $6 \%$ of effect for CEb-w99) and revealable toxicity for CEa (46\% of effect for CEb-s98 and 33\% of effect for CEb-w99), in contrast with the high toxicity, expressed as TU50, observed with M. galloprovincialis.

Both tests highlighted that:

- SG-s00 (about $60 \%$ of effect for sea urchin and TU50 of 1.4 for mussel) is more toxic than SG-w01 ( $<5 \%$ of effect for sea urchin and $29 \%$ of effect for mussel);

- BR-w99 (TU50=7 for sea urchin and TU50=4.3 for mussel) is more toxic than BR-s98 (TU50 $=2$ for sea urchin and TU50 $=2.6$ for mussel);

- OS-s98 (TU50=8 for sea urchin and TU50=5.8 for mussel) is more toxic than OS-w99 (TU50 $=7$ for sea urchin and TU50 $=2.8$ for mussel).

\section{Conclusions}

This paper allowed a valuation of embryotoxicity test with the autochthonous M. galloprovincialis for the lagoon of Venice. The use of a reference toxicant (copper) provided good intralaboratory reproducibility (EC50 mean value with standard deviation of $0.28 \pm 0.08 \mu \mathrm{M}$, $\mathrm{CV}=27, n=14$ ), when some variables such as different operators, different organism batches and sampling populations (natural, hatchery, open sea) were changed. Good quality of gametes and the long reproductive period (from November to May) were shown by natural lagoonal population; these characteristics were not found in hatchery population.

The application of embryotoxicity test to elutriates obtained from sediments of the lagoon of Venice revealed that the method is able to discriminate among sediments at different typologies and levels of contamination. Moreover, the test showed a relevant effect for almost all 
study sites and also in some samples from potential reference sites. The test does not seem to be influenced by sulphides in elutriates extracted from sediments, because the sulphide concentrations of elutriates were lower than the sensitivity threshold of the method. Ammonia does not seem to contribute to toxicity, except for five elutriate samples, characterized by high concentrations of ammonia, from sediments of industrial and estuarine sites (probably anthropogenic sources).

In conslusion, this work evidenced that the embryotoxicity test with M. galloprovincialis seems to be a promising tool for biomonitoring the lagoon of Venice, because of its high ecological representativity for this environment, its high sensitivity, comparable to embryotoxicity test with sea urchin, its execution rapidity $(48 \mathrm{~h})$ and its low costs, comparable to those for bioassays with the sea urchin and lower than those for Microtox test. Further investigation are needed to definitively validate this method for the lagoon.

\section{Acknowledgements}

This work was financed partly by Project 'Production, change and vulnerability of estuarine and lagoonal environments of Adritic Sea', partly by 'Orizzonte 2023 Project' and partly by the Consorzio Ricerche Laguna (Co.Ri.La.) of Venice (Italy). The authors are very grateful to D. Marchetto. Gabriel Walton revised the English text.

\section{References}

[1] US EPA, US ACE. Evaluation of dredged material proposed for discharge in waters of the US - testing manual. US Environmental Protection Agency and US Army Corps of Engineers. EPA/823-B-94/002, Washington, DC (1998).

[2] D.A. MacDonald, M.B. Matta, L.J. Field, C. Cairncross, M.D. Munn. The coastal resource coordinator's bioassessment manual. NOAA report no. hazmat 93-1, Seattle, Washington, USA (1992).

[3] J.P. Giesy, R.A. Hoke. Freshwater sediment toxicity bioassessment: rationale for species selection. J. Great Lakes Res., 15, 539-569 (1989).

[4] J.O. Lamberston, T.H. De Witt, R.C. Swartz. Assessment of sediment toxicity to marine benthos. In Sediment Toxicity Assessment, Burton, G.A., Jr. (Ed.), pp. 183-211 Lewis Publisher (1992).

[5] P.M. Chapman, F. Wang. Assessing sediment contamination in estuaries. Environ. Toxicol. Chem., 20(1), 3-22 (2002).

[6] ICES International Council for the Exploitation of the Sea. Report of the ICES Advisory Committee on the marine environment. ICES Cooperative Research Report 222, pp. 12-20 (1997).

[7] E. His, R. Beiras, M. Seaman. The assessment of aquatic contamination: bioassays with bivalve larvae. Adv. Marine Biol., 37, 1-178 (1999).

[8] M. Nendza. Inventory of marine biotest methods for the evaluation of dredged material and sediments. Chemosphere, 48(8), 865-883 (2002).

[9] G. Valli. Ciclo di maturità sessuale in Mytilus galloprovincialis Lmk di Duino (Trisete). Bol. Pesca Piscic. Idrobiol., 26(1-2), 260-265 (1971).

[10] L. Da Ros, M. Bressan, M.G. Marin. Reproductive cycle of the mussel (Mytilus galloprovincialis Lmk) in Venice lagoon (North Adriatic). Bol. Zool., 52, 223-229 (1985).

[11] D.R. Lee. Reference toxicants in quality control of aquatic bioassays. In Aquatic Invertebrate Bioassays, ASTM STP 715, Buikema, A.L., Jr. and Cairns, J., Jr. (Ed.), pp. 188-199, American Society for Testing and Materials, Philadelphia (1980).

[12] T.W. Neiheisel, M.E. Young. Use of three artificial salts to mantain fertile sea urchins (Arbacia punctulata) and to conduct fertilization tests with copper and sodium dodecyl sulfate. Environ. Toxicol. Chem., 11, 1179-1185 (1992).

[13] D.J. Klemm, G. Morrison, T. Norberg-King, W. Peltier, M. Heber. Short-term methods for estimating the chronic toxicity of effluents and receiving water to marine and estuarine organisms. US EPA, 600-4-91-003, Cincinnati, Ohio (1994).

[14] A. Volpi Ghirardini, A. Arizzi Novelli. A sperm cell toxicity test procedure for the Mediterranean species Paracentrotus lividus (Echinodermata: Echinoidea). Environ. Technol., 22, 439-445 (2001).

[15] E. His, R.N.L. Seaman, R. Beiras. A simplified bivalve larval bioassay method for seawater quality assessment. Wat. Res., 31, 351-355 (1997).

[16] US EPA. Short-term methods for estimating the chronic toxicity of effluents and receiving waters to west coast marine and estuarine organisms. EPA/600/R-95/136, Cincinnati, Ohio, USA (1995). 
[17] ASTM. Standard guide for conducting static acute toxicity tests starting with embryos of four species of saltwater bivalve molluscs. E724-98, pp. 21 (1998).

[18] J. Reardon, J.A. Foreman, R.L. Searcy. New reactants for the colorimetric determination of ammonia. Clin. Chim. Acta, 14(3), 203-205 (1966).

[19] A. Volpi Ghirardini, A. Arizzi Novelli, D. Tagliapietra. Sediment toxicity assessment in the Lagoon of Venice (Italy) using Paracentrotus lividus (Echinodermata: Echinoidea) fertilization and embryo bioassays. Environ. Int., in press.

[20] Venice Water Authority. Mappatura dell'inquinamento dei fondali lagunari Project (1998-1999), Ministry of Public Works - Venice Water Authority - Consorzio Venezia Nuova, Final Report (1999).

[21] A. Volpi Ghirardini, A. Arizzi Novelli, C. Losso, P.F. Ghetti. Sea urchin toxicity bioassays for sediment quality assessment in the Lagoon of Venice (Italy). Chem. Ecol., 19(2-3), 99-111 (2003).

[22] M.A. Hamilton, R.C. Russo, R.V. Thurston. Trimmed Spearman-Karber method for estimating median lethal concentrations in toxicity bioassays. Environ. Sci. Technol., 12, 714-720 (1978).

[23] G.T. Ankley, A. Katko, J.W. Arthur. Identification of ammonia as an important sediment-associated toxicant in the Lower Fox River and Green Bay, Wisconsin. Environ. Toxicol. Chem., 9, 313-322 (1990).

[24] R.S. Carr, E.R. Long, H.L. Windom, D.C. Chapman, G. Thursby, G.M. Sloane, D.A. Wolfe. Sediment quality assessment studies of Tampa Bay, Florida. Environ. Toxicol. Chem., 7, 1218-1231 (1996).

[25] F.W. Whiteman, G.T. Ankley, M.D. Kahl, D.M. Rau, M.D. Balcer. Evaluation of interstitial water as a route of exposure for ammonia in sediment tests with benthic macroinvertebrates. Environ. Toxicol. Chem., 15, 794-801 (1996).

[26] B.M. Phillips, B.S. Anderson, J.W. Hunt. Measurement and distribution of interstitial and overlying water ammonia and hydrogen sulfide in sediment toxicity tests. Marine Environ. Res., 44, 117-126 (1997).

[27] P. Cesari. I molluschi della laguna di Venezia, p. 189, Arsenale, Verona, Italy (1994). 